\section{Modulation of Radiation-Induced NADPH Oxidases in Rat's Heart Tissues by Melatonin}

\author{
Tayebeh Aryafar ${ }^{1 \oplus}$, Peyman Amini², Saeed Rezapoor², Dheyaul- \\ deen Shabeeb³, Ahmed Eleojo Musa4, Masoud Najafi5*(•, Al- \\ ireza Shirazi $i^{1,6}$
}

\begin{abstract}
Background: Experimental studies have shown that infiltration of inflammatory cells as well as upregulation of some cytokines play a central role in the development of late effects of ionizing radiation in heart tissues. Evidences have shown that an increased level of TGF- $\beta$ has a direct correlation with late effects of exposure to ionizing radiation such as chronic oxidative stress and fibrosis. Recent studies have shown that TGF- $\beta$, through upregulation of pro-oxidant enzymes such as NOX2 and NOX4, promotes continuous ROS production and accumulation of fibrosis.

Objective: In present study, we aimed to evaluate the expression of NOX2 and NOX4 signaling pathways as well as possible modulatory effects of melatonin on the expression of these genes.

Material and Methods: In this experimental study, four groups of 20 rats (5 in each) were used as follows; G1: control; G2: melatonin; G3: radiation; G4: radiation + melatonin. $100 \mathrm{mg} / \mathrm{kg}$ of melatonin was administrated before irradiation of heart tissues with 15 Gy gamma rays. 10 weeks after irradiation, heart tissues were collected for real-time Polymerase chain reaction (PCR).

Results: Results showed a significant increase in the expression of TGF- $\beta$, Smad2, NF-kB, NOX2 and NOX4. The upregulation of NOX2 was more obvious by 20 -fold compared to other genes. Except for TGF- $\beta$, melatonin could attenuate the expression of other genes.

Conclusion: This study indicated that exposure of rat's heart tissues to radiation leads to upregulation of TGF- $\beta$-NOX 4 and TGF- $\beta$-NOX2 pathways. Melatonin, through modulation of these genes, may be able to alleviate radiation-induced chronic oxidative stress and subsequent consequences.
\end{abstract}

Citation: Aryafar T, Amini P, Rezapoor S, Shabeeb D, Eleojo Musa A, Najafi M, Shirazi AR. Modulation of Radiation-Induced NADPH Oxidases in Rat's Heart Tissues by Melatonin. J Biomed Phys Eng. 2021;11(4):465-472. doi: 10.31661/jbpe.v0i0.1094.

Keywords

Radiation; Melatonin; Heart; NADPH Oxidase 2; NADPH Oxidase 4

\section{Introduction}

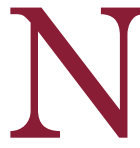
owadays, exposure to ionizing radiation is unavoidable. On the other hand, there are serious concerns related to carcinogenesis and also non-cancer diseases following exposure to ionizing radiation [1]. Exposure to ionizing radiation may result from medical applications or through accidental events such as nuclear or radiological disasters [2]. Heart diseases are among the most serious diseases for people exposed to ionizing radiation [3]. Some of these exposures
${ }^{1} \mathrm{PhD}$, Department of Medical Physics and Biomedical Engineering, Faculty of Medicine, Tehran University of Medical Sciences, Tehran, Iran ${ }^{2} \mathrm{MSc}$, Department of Radiology, Faculty of

Paramedical, Tehran University of Medical Sciences, Tehran, Iran

${ }^{3} \mathrm{PhD}$, Department of

Physiology, College of

Medicine, University of

Misan, Misan, Iraq

${ }^{4} \mathrm{PhD}$, Research Center

of Molecular and Cel-

lular Imaging, Tehran

University of Medical

Sciences (International

Campus), Tehran, Iran

${ }^{5} \mathrm{PhD}$, Radiology and

Nuclear Medicine

Department, School of

Paramedical Sciences,

Kermanshah University

of Medical Sciences,

Kermanshah, Iran

${ }^{6} \mathrm{PhD}$, Cancer Research

Centre, Cancer Insti-

tute, Tehran University

of Medical Sciences,

Tehran, Iran

*Corresponding author: Masoud Najafi

Department of Medical

Physics and Biomedical

Engineering, Faculty of

Medicine, Tehran Univer-

sity of Medical Sciences,

Tehran, Iran

E-mail: najafi_ma@

yahoo.com

Received: 29 December 2018 Accepted: 18 February 2019 
can be through diagnostic radiography and nuclear medicine procedures for screening or detection of diseases. Computed tomography and cardiac angiography can cause exposure of heart to a high dose of ionizing radiation $[4,5]$. In addition, yearly, millions of people receive high doses of ionizing radiation for treatment of cancer. Heart injury is a probable risk for patients with chest cancer, following direct irradiation of the heart [6]. There is potent evidence for cardiac disorders following exposure to ionizing radiation [7].

Several years after the atomic bomb explosion in Hiroshima and Nagasaki, epidemiological studies have shown increased death due to cardiac diseases. Further analyses have shown that people who had been exposed to atomic bomb explosions are at a higher risk for cardiovascular diseases such as atherosclerosis, heart failure, ischemia [8]. Studies have also shown a significant increase in heart diseases for patients with lung and patients with left breast cancers compared to those with right breast cancer that underwent radiotherapy $[9$, 10]. Experimental studies have revealed that exposure of heart to ionizing radiation leads to changes in the level of several immune mediators and cytokines, which facilitate the infiltration of inflammatory cells such as mast cells, macrophages and lymphocytes [11]. It has been proposed that chronic upregulation of some cytokines such as IL- 1 and TGF- $\beta$ is involved in the pathogenesis of heart tissue after exposure to radiation [12]. These cytokines, through changes in the expression of some pro-fibrotic genes, elevate the stiffness of heart muscles, leading to increased risk of ischemia and heart failure [13].

In recent years, it has been shown that chronic oxidative stress following exposure to ionizing radiation mediate several consequences of radiation damage in exposed cells. Based on studies, inflammatory cells facilitate the production of ROS through some pro-oxidant enzymes such as NADPH oxidase, cyclooxygenase-2 (COX-2) and mitochondria. In addi- tion, macrophages may induce the production of nitric oxide by nitric oxide synthase (NOS) enzymes [14]. TGF- $\beta$ has ability to stimulate the upregulation of some pro-oxidants such as COX-2, NADPH oxidase (NOX)-1, NOX2 and NOX4 [15]. Upregulation of TGF- $\beta-$ NOX4 pathway has been observed in mice bone marrow cells after whole body irradiation [16]. Increased regulation of TGF- $\beta$ - NOX 4 is responsible for chronic oxidative injury in bone marrow and brain cells $[17,18]$. So far, some agents such as metformin and resveratrol have been proposed for modulation of NOX4 upregulation following exposure to radiation $[19,20]$. Melatonin as a natural body hormone has shown ability to modulate various inflammatory cytokines and pro-oxidant enzymes, leading to alleviation of radiation injury [21, 22]. This study aims to evaluate the possible changes in the expression of two important subfamilies of NADPH oxidase enzymes, including NOX2 and NOX4. Moreover, we detected possible modulatory effect of melatonin on the expression of these signaling pathways.

\section{Material and Methods}

\section{Experimental design}

In this experimental study, 20 male Wistar rat weighing $200 \pm 20 \mathrm{~g}$ were divided into 4 groups (5 rats in each). Group 1 was control that this group did not receive any radiation or melatonin; group 2was melatonin treatment, which this group only received melatonin without radiation. Group 3 was radiation that rats received 15 Gy gamma rays radiation to heart tissue; group 4 was radiation plus melatonin treatment, which rats received $100 \mathrm{mg} /$ $\mathrm{kg}$ melatonin and after 30 minutes, their heart tissues were exposed to 15 Gy gamma rays radiation. All rats were kept under standard conditions such as temperature $\left(22^{\circ} \mathrm{C}\right)$ and humidity (55\%). In addition, rats were kept under 12-hour light (5AM-5PM) and dark (5PM-5AM) cycle. 10 weeks following irradiation, all rats were killed at same time and 
Modulation of NADPH Oxidase in Heart by Melatonin

their heart tissues were removed. They were frozen at $-70^{\circ} \mathrm{C}$ for real-time PCR. All procedures of animal study were in accordance with the ethical guidelines of Tehran University of Medical Sciences, Tehran, Iran.

\section{Drug treatment and irradiation}

Melatonin was purchased from Sigma Aldrich Company (USA). It was dissolved in $15 \%$ ethanol at a concentration of $20 \mathrm{mg}$ per milliliter. Each rat received $1 \mathrm{ml}$ intraperitoneal injection of melatonin solution equal to $100 \mathrm{mg} / \mathrm{kg} 30$ minutes before irradiation. In addition, before irradiation, rats received a combination of ketamine and xylazine as anesthesia for fixation of rats during irradiation. After anesthesia, rats were placed supine on the desk of cobalt-60 gamma rays source. Irradiation was performed locally to the chest area of rats at a source to skin distance (SSD) of 60 $\mathrm{cm}$ and a dose rate of $104 \mathrm{cGy} / \mathrm{min}$.

\section{Real-time PCR}

Heart tissues were moved to room temperature for defreezing. Afterwards, the tissues were homogenated and total RNA extracted using TRIzol reagent (Sinagene, Iran). cDNA was synthesized from total RNA using cDNA synthesis kit (Geneall, South Korea). The expression of each gene was detected using Applied Biosystems Real-time PCR (USA). Primers were designed using Generunner software and then blasted in NCBI. The primer sequences are shown in Table 1.
Statistical analysis

Data were reported as mean \pm standard deviation. For the evaluation of significance differences between mean of different groups, we used SPSS software version 24. Analysis of variance (ANOVA) was used for evaluating the significant differences in the expression of genes among different groups. $\mathrm{P}$ value $<0.05$ was considered statistically significant.

\section{Results}

Real-time PCR results showed that when rats were exposed to gamma rays, the expression of TGF- $\beta$ increases significantly (1.94 \pm 0.37 fold $)$ compared to control $(p<0.05)$. Treatment with melatonin before irradiation could not reduce the expression of TGF- $\beta$ compared to radiation group $(1.36 \pm 0.26)$. The expression of Smad2 increased following irradiation of rat's heart tissues $(5.72 \pm 0.55$ fold) $(\mathrm{p}<0.001)$. However, the expression of Smad2 was attenuated when rats were treated with melatonin before irradiation $(4.11 \pm 0.79)$ $(p=0.007)$. Irradiation of heart tissues led to $3.13 \pm 0.75$ fold increase in the expression of NF-kB compared to control group $(p<0.001)$. However, administration of melatonin could reduce the expression of NF-kB $(1.67 \pm 0.19$ fold) compared to control group $(\mathrm{p}<0.006)$.

Real-time PCR results showed that when rats were irradiated with gamma rays, the expression of NOX2 increased significantly compared to control group $(20.10 \pm 4.20$ fold $)$ $(p<0.001)$. However, when rats were treated

Table 1: The sequences of primers for real-time Polymerase chain reaction (PCR).

\begin{tabular}{cll} 
Genes & \multicolumn{1}{c}{ Forward sequence } & \multicolumn{1}{c}{ Reverse sequence } \\
\hline TGF $\boldsymbol{B} \mathbf{1}$ & TGCACCATCTTCAAAACAGGG & CAGCTGACTGCTTTTCTGTAGT \\
\hline NF-kB & AATTGCCCCGGCAT & TCCCGTAACCGCGTA \\
\hline SMAD2 & TCTCCGGCTGAACTGTCTCCTA & GCGATTGAACACCAAATGCA \\
\hline NOX2 & CTGCCAGTGTGTCGGATCT & TGTGAATGGCCGTGTGAAGT \\
\hline NOX4 & GGATCACAGAAGGTCCCTAGC & AGAAGTTCAGGGCGTTCACC \\
\hline GAPDH & AGTGCCAGCCTCGTCTCATA & ATGAAGGGGTCGTTGATGGC
\end{tabular}

TGF $\beta$ R1: Transforming growth factor $\beta$ receptor 1, NF-kB: Nuclear factor kappa B, SMAD2: Mothers against decapentaplegic homolog 2, NOX2: NADPH Oxidase 2, NOX4: NADPH Oxidase 4, GAPDH: Glyceraldehyde 3-phosphate dehydrogenase 
with melatonin before exposure to gamma rays, the expression of NOX2 was reduced significantly compared to radiation group $(6.91 \pm 4.40)(p=0.001)$. Results of NOX4 gene expression showed that the expression of this gene increased significantly compared to control $(2.92 \pm 0.63$ fold $)(p=0.001)$. However, when melatonin was administered before irradiation of heart tissues, the expression of NOX4 was attenuated compared to radiation without melatonin group (1.98 \pm $0.48)(p<0.05)$. Results of real-time PCR also showed that administration of melatonin did not induce the expression of any of the mentioned genes in rat's heart tissues (Figure 1).

\section{Discussion}

Some epidemiological studies have shown that exposure to even low doses of ionizing radiation may cause increased incidence of car-
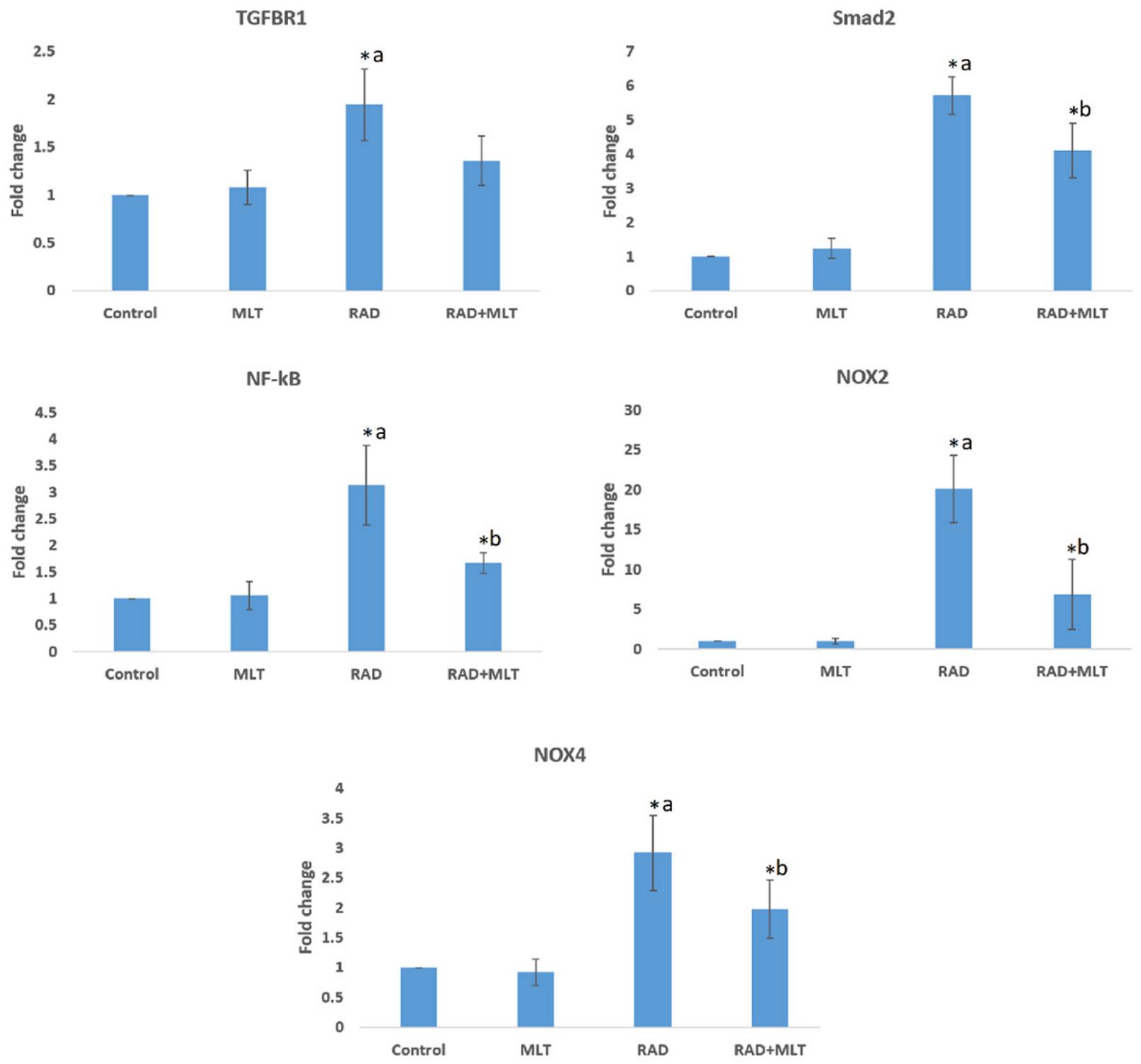

Figure 1: The expression of transforming growth factor $\beta$ (TGF- $\beta$ ), Nuclear factor kappa B (NF-kB), Mothers against decapentaplegic homolog 2 (SMAD2), NADPH Oxidase 2 (NOX2) and NADPH Oxidase 4 (NOX4) following rat's heart irradiation and treatment with melatonin. (Analysis of variance (ANOVA), ${ }^{*}=p<0.05$, a: significant compared to control group; b: significant compared to radiation group). 
diac diseases [23]. Studies proposed that the incidence of heart diseases has a direct relation with received radiation dose to heart tissue. [24] Experimental studies have shown that exposure to ionizing radiation leads to increased immune cells as well as pro-inflammatory and pro-fibrotic cytokines, which mediate appearance of inflammation and fibrosis [25]. These could lead to changes in the normal structure of heart tissues. Some studies have shown that radiation causes hypertrophy, pericarditis and fibrosis. Fibrosis in the coronary and carotid arteries may disrupt normal blood supply of heart muscles, leading to ischemia and heart failure. The time of appearance of these signs may be very long and detectable years after exposure to ionizing radiation [26]. In vivo studies have shown that exposing the heart to ionizing radiation leads to upregulation of some inflammatory and pro-oxidant factors such as IL-1, TNF- $\alpha$, COX-2, intercellular adhesion molecule 1 (ICAM-1), vascular cell adhesion molecule-1 (VCAM-1), thrombomodulin (TM), etc [27-29]. In addition, upregulation of endothelin (ET)-1 following infiltration of mast cells plays a key role in oxidative stress and several late effects such as hypertrophy, inflammation, etc [30].

In this study, we showed that exposure to ionizing radiation led to significant upregulation of NOX2 and NOX4 pathways in rat's heart tissues. Previous studies have proposed that TGF- $\beta$, through downstream genes such as NF-kB and Smad2 has ability to induce the regulation of these genes $[31,32]$. Results of this study showed upregulation of these genes. The most obvious change in the gene expression was observed for NOX2 by 20 -fold increase. NOX2 is a membrane dependent enzyme that produces hydrogen peroxidase following stimulation by some immune activators. Some in vitro studies have shown that upregulation of NOX2 is involved in chronic oxidative stress and genomic instability in irradiated as well as bystander cells [33]. NOX4 plays a key role in chronic production of free radicals. Upregulation of NOX2 and NOX4 was revealed for 2 months following whole body irradiation of mice. In addition, it was found that upregulation of these genes was associated with chromosome aberrations, an alarm of carcinogenesis [18].

Melatonin has shown ability to attenuate inflammation as well as activation of prooxidant enzymes [34-36]. It has also shown ability to attenuate radiation toxicity in bone marrow cells through modulation of TGF- $\beta$ NOX4 pathway [37]. In addition, melatonin can attenuate upregulation of COX-2, prostaglandins, iNOS as well as some other proinflammatory and pro-fibrotic mediators that may be involved in radiation toxicity $[38,39]$. In present study, we showed that melatonin, through modulation of NADPH oxidase, especially NOX2, reduces the risk of radiationinduced cardiac injury.

\section{Conclusion}

This study showed that exposure of rat's heart tissues to ionizing radiation leads to significant upregulation of TGF- $\beta$-NOX4 and TGF- $\beta$-NOX2 pathways. The most obvious change was observed for NOX2 by 20 -fold increase. Administration of melatonin before irradiation caused significant attenuation of both NOX2 and NOX4. As previous studies have confirmed that the upregulation of these genes is involved in radiation toxicity, it is possible that melatonin, through modulation of these genes, alleviates radiation-induced chronic oxidative stress and subsequent consequences such as fibrosis.

\section{Acknowledgment}

Tehran University of Medical Sciences and Health Service; Grant Number: 32619.

\section{Conflict of Interest}

None

\section{References}

1. Bostrom PJ, Soloway MS. Secondary cancer after 
radiotherapy for prostate cancer: should we be more aware of the risk? Eur Urol. 2007;52:97382. doi: 10.1016/j.eururo.2007.07.002. PubMed PMID: 17644245.

2. Krivokrysenko VI, Toshkov IA, Gleiberman AS, Krasnov P, Shyshynova I, Bespalov I, et al. The Toll-like receptor 5 agonist entolimod mitigates lethal acute radiation syndrome in non-human primates. PLOS One. 2015;10:e0135388. doi: 10.1371/journal.pone.0135388.

3. Madan R, Benson R, Sharma DN, Julka PK, Rath GK. Radiation induced heart disease: Pathogenesis, management and review literature. J Egypt Natl Canc Inst. 2015;27:187-93. doi: 10.1016/j. jnci.2015.07.005. PubMed PMID: 26296945.

4. Gerber TC, Kantor B, McCollough CH. Radiation dose and safety in cardiac computed tomography. Cardiol Clin. 2009;27:665-77. doi: 10.1016/j.ccl.2009.06.006. PubMed PMID: 19766923. PubMed PMCID: PMC2749002.

5. Sun Z, Aziz YF, Ng KH. Coronary CT angiography: how should physicians use it wisely and when do physicians request it appropriately? Eur J Radiol. 2012;81:e684-7. doi: 10.1016/j. ejrad.2011.06.040. PubMed PMID: 21724353.

6. Taunk NK, Haffty BG, Kostis JB, Goyal S. Radiation-induced heart disease: pathologic abnormalities and putative mechanisms. Front $\mathrm{On}$ col. 2015;5:39. doi: 10.3389/fonc.2015.00039. PubMed PMID: 25741474. PubMed PMCID: PMC4332338.

7. Yusuf SW, Venkatesulu BP, Mahadevan LS, Krishnan S. Radiation-Induced Cardiovascular Disease: A Clinical Perspective. Front Cardiovasc Med. 2017;4:66. doi: 10.3389/fcvm.2017.00066. PubMed PMID: 29124057. PubMed PMCID: PMC5662579.

8. Shimizu Y, Kodama K, Nishi N, Kasagi F, Suyama A, Soda M, et al. Radiation exposure and circulatory disease risk: Hiroshima and $\mathrm{Na}-$ gasaki atomic bomb survivor data, 1950-2003. BMJ. 2010;340:b5349. doi: 10.1136/bmj.b5349. PubMed PMID: 20075151. PubMed PMCID: PMC2806940.

9. Ming X, Feng $Y$, Yang C, Wang W, Wang P, Deng J. Radiation-induced heart disease in lung cancer radiotherapy: A dosimetric update. Medicine (Baltimore). 2016;95:e5051. doi: 10.1097/ MD.0000000000005051. PubMed PMID: 27741117. PubMed PMCID: PMC5072944.

10. Sardaro A, Petruzzelli MF, D’Errico MP, Grimaldi
L, Pili G, Portaluri M. Radiation-induced cardiac damage in early left breast cancer patients: risk factors, biological mechanisms, radiobiology, and dosimetric constraints. Radiother Oncol. 2012;103:133-42. doi: 10.1016/j.radonc.2012.02.008. PubMed PMID: 22391054.

11. Seyyednejad F, Rezaee A, Haghi S, Goldust M. Survey of pre-inflammation cytokines levels in radiotherapy-induced-mucositis. Pak J Biol Sci. 2012;15:1098-101. doi: 10.3923/ pjbs.2012.1098.1101. PubMed PMID: 24261128.

12. Boerma M, Sridharan V, Mao XW, Nelson GA, Cheema AK, Koturbash I, et al. Effects of ionizing radiation on the heart. Mutat Res. 2016;770:31927. doi: 10.1016/j.mrrev.2016.07.003. PubMed PMID: 27919338. PubMed PMCID: PMC5144922.

13. Khan R, Sheppard R. Fibrosis in heart disease: understanding the role of transforming growth factor-beta in cardiomyopathy, valvular disease and arrhythmia. Immunology. 2006;118:1024. doi: 10.1111/j.1365-2567.2006.02336.x. PubMed PMID: 16630019. PubMed PMCID: PMC1782267.

14. Chai Y, Calaf GM, Zhou H, Ghandhi SA, Elliston $\mathrm{CD}$, Wen $\mathrm{G}$, et al. Radiation induced COX-2 expression and mutagenesis at non-targeted lung tissues of gpt delta transgenic mice. $\mathrm{Br} J \mathrm{Can}-$ cer. 2013;108:91-8. doi: 10.1038/bjc.2012.498. PubMed PMID: 23321513. PubMed PMCID: PMC3553512.

15. Mortezaee K, Goradel NH, Amini P, Shabeeb D, Musa AE, Najafi $M$, et al. NADPH oxidase as a target for modulation of radiation response; implications to carcinogenesis and radiotherapy. Curr Mol Pharmacol. 2019;12:50-60. doi: 10.2 174/1874467211666181010154709.

16. Chang J, Feng W, Wang Y, Luo Y, Allen AR, Koturbash I, et al. Whole-body proton irradiation causes long-term damage to hematopoietic stem cells in mice. Radiat Res. 2015;183:240-8. doi: 10.1667/RR13887.1. PubMed PMID: 25635345. PubMed PMCID: PMC4992474.

17. Collins-Underwood JR, Zhao W, Sharpe JG, Robbins ME. NADPH oxidase mediates radiation-induced oxidative stress in rat brain microvascular endothelial cells. Free Radic Biol Med. 2008;45:929-38. doi: 10.1016/j.freeradbiomed.2008.06.024. PubMed PMID: 18640264. PubMed PMCID: PMC2603423. 
Modulation of NADPH Oxidase in Heart by Melatonin

18. Pazhanisamy SK, Li H, Wang Y, Batinic-Haberle I, Zhou D. NADPH oxidase inhibition attenuates total body irradiation-induced haematopoietic genomic instability. Mutagenesis. 2011;26:4315. doi: 10.1093/mutage/ger001. PubMed PMID: 21415439. PubMed PMCID: PMC3081334.

19. Carsten RE, Bachand AM, Bailey SM, Ullrich RL. Resveratrol reduces radiation-induced chromosome aberration frequencies in mouse bone marrow cells. Radiat Res. 2008;169:633-8. doi: 10.1667/RR1190.1. PubMed PMID: 18494544. PubMed PMCID: PMC2692544.

20. Xu G, Wu H, Zhang J, Li D, Wang Y, Wang Y, et al. Metformin ameliorates ionizing irradiationinduced long-term hematopoietic stem cell injury in mice. Free Radic Biol Med. 2015;87:1525. doi: 10.1016/j.freeradbiomed.2015.05.045. PubMed PMID: 26086617. PubMed PMCID: PMC4707049.

21. Ahmadi Z, Ashrafizadeh M. Melatonin as a potential modulator of Nrf2. Fundam Clin Pharmacol. 2020;34(1):11-19. doi: 10.1111/fcp.12498.

22. Ashrafizadeh M, Ahmadi Z, et al. Nanoparticles Targeting STATs in Cancer Therapy. Cells. 2019;8(10):1158. doi: 10.3390/cells8101158.

23.Zielinski JM, Ashmore PJ, Band PR, Jiang H, Shilnikova NS, Tait VK, et al. Low dose ionizing radiation exposure and cardiovascular disease mortality: cohort study based on Canadian national dose registry of radiation workers. Int $J$ Occup Med Environ Health. 2009;22:27-33. doi: 10.2478/v10001-009-0001-z. PubMed PMID: 19329385.

24. Little MP. Cancer and non-cancer effects in Japanese atomic bomb survivors. I Radiol Prot. 2009;29:A43-59. doi: 10.1088/09524746/29/2A/S04. PubMed PMID: 19454804.

25. Burnette B, Weichselbaum RR. Radiation as an immune modulator. Semin Radiat Oncol. 2013;23:273-80. doi: 10.1016/j.semradonc.2013.05.009. PubMed PMID: 24012341.

26. Liu LK, Ouyang W, Zhao X, Su Sh F, Yang Y, Ding WJ, et al. Pathogenesis and Prevention of Radiation-induced Myocardial Fibrosis. Asian Pac J Cancer Prev. 2017;18:583-7. doi: 10.22034/APJCP.2017.18.3.583. PubMed PMID: 28440606. PubMed PMCID: PMC5464468.

27. Mathias D, Mitchel RE, Barclay $M$, Wyatt $H$, Bugden M, Priest ND, et al. Low-dose irradiation affects expression of inflammatory markers in the heart of ApoE -/- mice. PLoS One. 2015;10:e0119661. doi: 10.1371/journal. pone.0119661. PubMed PMID: 25799423. PubMed PMCID: PMC4370602.

28. Patties I, Haagen J, Dorr W, Hildebrandt G, Glasow A. Late inflammatory and thrombotic changes in irradiated hearts of C57BL/6 wildtype and atherosclerosis-prone ApoE-deficient mice. Strahlenther Onkol. 2015;191:172-9. doi: 10.1007/s00066-014-0745-7. PubMed PMID: 25200359 .

29. Hoving S, Heeneman S, Gijbels MJ, Te Poele $\mathrm{JA}$, Visser N, Cleutjens $\mathrm{J}$, et al. Irradiation induces different inflammatory and thrombotic responses in carotid arteries of wildtype C57BL/6J and atherosclerosis-prone ApoE(-/-) mice. Radiother Oncol. 2012;105:365-70. doi: 10.1016/j. radonc.2012.11.001. PubMed PMID: 23245647.

30. Eldabaje R, Le DL, Huang W, Yang LX. Radiation-associated Cardiac Injury. Anticancer Res. 2015;35:2487-92. PubMed PMID: 25964521.

31. Murillo MM, Carmona-Cuenca I, Del Castillo G, Ortiz C, Roncero C, Sanchez A, et al. Activation of NADPH oxidase by transforming growth factor-beta in hepatocytes mediates upregulation of epidermal growth factor receptor ligands through a nuclear factor-kappaB-dependent mechanism. Biochem J. 2007;405:2519. doi: 10.1042/BJ20061846. PubMed PMID: 17407446. PubMed PMCID: PMC1904531.

32. Samarakoon R, Overstreet JM, Higgins PJ. TGF- $\beta$ signaling in tissue fibrosis: redox controls, target genes and therapeutic opportunities. Cell Signal. 2013;25:264-8. doi: 10.1016/j. cellsig.2012.10.003.

33. Yahyapour $R$, Salajegheh $A$, Safari $A$, Amini $P$, Rezaeyan A, Amraee A, et al. Radiation-induced Non-targeted Effect and Carcinogenesis; Implications in Clinical Radiotherapy. J Biomed Phys Eng. 2018;8:435-46. PubMed PMID: 30568933. PubMed PMCID: PMC6280111.

34. Ataee $R$, Shokrzadeh M, Jafari-Sabet M, Nasrabadi Nasri N, Ataie A, Haghi Aminjan $\mathrm{H}$. The role of melatonin and melatonin receptors in pharmacology and pharmacotherapy of cancer. Austin Oncol. 2017;2:1015.

35. Haghi-Aminjan H, Asghari MH, Farhood B, Rahimifard M, Hashemi Goradel N, Abdollahi M. The role of melatonin on chemotherapy-induced reproductive toxicity. J Pharm Pharmacol. 2018;70:291-306. doi: 10.1111/jphp.12855. PubMed PMID: 29168173. 
Tayebeh Aryafar, Peyman Amini, Saeed Rezapoor, et al

36. Haghi-Aminjan H, Farhood B, Rahimifard M, Didari T, Baeeri M, Hassani S, et al. The protective role of melatonin in chemotherapy-induced nephrotoxicity: a systematic review of non-clinical studies. Expert Opin Drug Metab Toxicol. 2018;14:93750. doi: 10.1080/17425255.2018.1513492. PubMed PMID: 30118646.

37. Li D, Tian Z, Tang W, Zhang J, Lu L, Sun Z, et al. The Protective Effects of 5-Methoxytryptaminealpha-lipoic Acid on Ionizing Radiation-Induced Hematopoietic Injury. Int J Mol Sci. 2016;17. doi: 10.3390/ijms17060935. PubMed PMID:
27314327. PubMed PMCID: PMC4926468.

38. Favero G, Franceschetti L, Bonomini F, Rodella LF, Rezzani R. Melatonin as an Anti-Inflammatory Agent Modulating Inflammasome Activation. Int $J$ Endocrinol. 2017;2017:1835195. doi: 10.1155/2017/1835195. PubMed PMID: 29104591. PubMed PMCID: PMC5643098.

39. Esposito E, Cuzzocrea S. Antiinflammatory activity of melatonin in central nervous system. Curr Neuropharmacol. 2010;8:228-42. doi: 10.2174/157015910792246155. PubMed PMID: 21358973. PubMed PMCID: PMC3001216. 